\title{
Water-pipe tobacco epidemic in tobacco naive communities: Experience from Ethiopia*
}

\author{
Molla Gedefaw $^{1 \#}$, Amanuel Eshete ${ }^{1}$, Mekonnen Aychiluhem ${ }^{1}$, Mr. Telake Azale ${ }^{2}$ \\ ${ }^{1}$ GAMBY College of Medical Sciences, Bahir Dar, Ethiopia \\ ${ }^{2}$ University of Gondar, Gondar, Ethiopia \\ Email: "
}

Received 14 August 2013; revised 14 September 2013; accepted 21 September 2013

Copyright (c) 2013 Molla Gedefaw et al. This is an open access article distributed under the Creative Commons Attribution License, which permits unrestricted use, distribution, and reproduction in any medium, provided the original work is properly cited.

\section{ABSTRACT}

Water-pipe tobacco (WPT) is a public health threat of the $21^{\text {st }}$ century. As a fashion, it swiftly spreads to all corners of the world in no more than two decades. It is a new phenomenon for Ethiopia in general and for Amhara National Regional State in particular. The major objective of this study was to gain in-depth baseline information about water-pipe tobacco smoking practice in Bahir Dar City, 2012. An explorative study was conducted at Bahir Dar City-capital of Amhara National Regional State. It is home for one of the largest universities in the country with more than 40,000 students. Of the total 50 WPT lounges, six were identified based on their customer variety, and loaded by the help of police officers who had ample experience in fighting the expansion of WPT smoking in the city. A total of $\mathbf{1 1 5}$ people participated in this study. In-depth interviews and focus group discussions (FGD) were conducted, and the tape recorded data were thematically analyzed. More than $80 \%$ of the study participants were below 40 Years, and more than $30 \%$ of the total study participants were students. The profession of the remaining participants ranges from daily laborers to university instructors. Females accounted for $37.39 \%$. The following factors were found to be pertinent for rapid increment of water-pipe tobacco smoking: geographic and economic accessibility, peer pressure, deceiving characteristics of WPTnon-irritant and aromatic, lack of knowledge, and absence of effective policy. The most outstanding findings of this study were the following: almost all of the

\footnotetext{
* Conflict of interests: Authors declared that they have no conflict of Interests.

Author's contribution: This manuscript is extracted from the Master's thesis (masters of public health) of Mr. Amanuel Eshtie. Dr. Malla Gedefaw was his principal advisor. Dr. Mekonnen Aychiluhm and Mr. Telake Azale were his co-advisors. All played their role perfectly.

${ }^{\#}$ Corresponding author.
}

study participants were tobacco naive and really unaware of the contents WPT; but about $94 \%$ of them had been khat chewers before they started with WPT smoking. In this region, khat had until recently been used by the Muslims only. WPT smoking is an even more recent phenomenon. "Khat stimulates, and WPT calms down," said study participants. That means by using the later as an antidote for the former, people start ruining their health with substances containing chemicals proven to be notorious to human health. This combination of deadly addictions seems to be peculiar to Ethiopia and appears to be a serious public health threat to tobacco naive communities in the region. Therefore, their rapid progression needs to be met with appropriate interventions urgently. It also warrants further investigations.

Keywords: Water-Pipe; Tobacco; Khat; Tobacco Naïve; Community; Epidemic

\section{INTRODUCTION}

World Health Organization declares tobacco as one of the greatest threats to global health. More than $30 \%$ of world's adult population is becoming consumers of tobacco. About 5 million people die prematurely from health consequences of tobacco use every year [1]. WHO warns that a billion people will die of adverse health effects of tobacco epidemic within the $21^{\text {st }}$ century unless effective majors are undertaken [2]. The public health challenge of tobacco is unique in that tobacco producers [1] undermine public health efforts because they gain unbelievably huge wealth, and power which enables them to endure all sorts of anti-tobacco policies, and campaigns.

The future seems even worse [1] because thanks to innovation of tobacco producing companies, tobacco seems to succeed in reaching every corner of the world in dif- 
ferent forms, and tastes more than ever before [3]. For instance, Nakhla pioneered the concept of aromatic molasses, and established itself as a number one producer of aromatic water-pipe tobacco. In 2011 alone, its total sales volume was approximately 24,000 tons which is equivalent to 24 billion cigarettes [4]. The company currently operates in up to 20 African countries including Algeria, Morocco, Nigeria, Tanzania and South Africa.

To make things worse, giant international tobacco producing companies showed interest in the production of aromatic water-pipe tobacco production. For instance, according to Euro Monitor (20 $0^{\text {th }}$ of November, 2012) [4], Japan Tobacco Inc. signed an agreement with Nakhlathe number one water-pipe tobacco manufacturer-based in Egypt, and Saudiarabia to produce water-wipe tobacco.

Although water-pipe tobacco smoking has a long history in the Middle-East, India, and North Africa, literature indicates that its resurgence coincides with the introduction of flavored water-pipe tobacco in the last decade of the $20^{\text {th }}$ century $[5,6]$. Water-pipe tobacco has different names such as Nargila, Hookah, Hubble-Bubble, Water Pipe and Shisha in deferent countries. In this paper we used water-pipe to cover all these different names as recommended by WHO regional office for eastern Mediterranean Region, 2006 [7].

From a public health point of view, we believe that the expansion of flavored water-pipe tobacco appears the most malignant of all tobacco forms. Having less irritant nature, different aroma, and taste $[3,8]$, it delivers all sorts of known and unknown harmful components of tobacco to children, tobacco naïve adults and elderly in many countries of the world [9]. Therefore, nowadays waterpipe tobacco smoking is declared as a global epidemic surrounded with lots of misconceptions $[3,5,10,11]$.

Cognizant of the debilitating health risks of tobacco, nations across the world are very much concerned about the rapid expansion of water-pipe tobacco smoking [3,11, 12]. This concern is actually well shared even among nations where water wipe-pipe tobacco smoking is considered as a tradition [6]. WHO warns that more than a billion people will die from adverse health effects of tobacco epidemic, and the major segment will be from the middle and low income countries [2].

Water-wipe tobacco (WPT) is a new phenomenon in Ethiopia in general, and in Amhara National Regional State in particular. This part of the country has been highly dominated with Coptic Orthodox Christian culture, and parents had the chance to nurture their children in a tobacco free environment. Unfortunately, however, what we currently observe in Bahir Dar City, the capital of Amhara National Regional State, is very much irritating, and bothersome. Because of geographic proximity to Sudan and Egypt where the number one water-pipe tobacco producing companies are based, Ethiopia will be probably one of the most affected countries in the horn of Africa.

The vulnerability of Ethiopia to WPT seems to be aggravated by the high consumption of khat (Catha edulis). Khat is an evergreen plant consumed mostly for stimulation, and recreation purposes. In Ethiopia, studies indicate that the plant is nowadays highly abused especially by the young people [13]. Therefore, it causes multitudes of health and social problems [14-16]. Besides, this plant is found to be an entry point to starting with other substances such as cigarettes and alcohol [13].

Hence, this explorative study was conducted to gain in-depth baseline information about water-pipe tobacco smoking practice in Bahir Dar city. The finding of this study will serve as a springboard for further studies. Moreover, it gives highlight about current practices of WPT smoking in the city which can help stimulate public health action to start checking the rapid expansion of WPT smoking in the horn of Africa.

\section{MATERIALS AND METHODS}

An explorative study was conducted in Bahir Dar City, the capital of Amhara National Regional State, Ethiopia from September to December, 2012. The city has a total population of 267,350. It is situated south of Lake Tana, and Blue Nile River. The Lake has several Orthodox Christian dominated historical heritages. Hence, it is one of the tourist attraction sites in Ethiopia. The farmers are nearly hundred percent Orthodox Christians. The city has one public university and several other private owned and public colleges. The university alone has also above 40,000 students.

Currently, the city has 17 Kebeles which is equivalent to a district. According to the records of the city police, there are about 50 water pipe smoking lounges in the city. Of these, nine of them were well known and hence visited by many people despite the fact that water-pipe smoking is not legal. Smokers, as well as lounge owners could be taken to police station and punished.

The study target of this research were water pipe smokers, lounge owners, and polices who were actively playing their respective roles in all kebeles of Bahir Dar City.

A total of 115 people participated in this study. These all water-pipe tobacco smokers were accessed at six lounges. These six sites were selected by the help of police officers, and community polices. Their selection was based on their customer variety and load.

In depth interview, observation, and focus group discussion were the data collection tools. An interview guide and observation checklist was prepared in English and translated into Amharic and then back into English by language experts. The data were collected by an experienced interviewer who by chance established good con- 
tact with police officers and some water-pipe tobacco smokers. Socio demographic characteristics were documented for all study participants.

Interviews, and focus discussions were tape recorded. Then the data were transcribed, and translated to English. Thematic analysis was carried out. A thematic analysis was analysis of choice for the purpose of this study because it offers an accessible and theoretically driven approach to analyzing qualitative data. A five days refresher training on principles of qualitative research, and qualitative data analysis was organized at the GAMBY College of Medical Sciences, and researchers participated in this training. The training was given by local scientists, and international experts invited from Berlin, and Heidelberg. Moreover, the proposal had been presented, and commented by experts at the GAMBY College of Medical Sciences. The college gives post graduate training in public health in collaboration with Bahir Dar, and Deberemarkos Universities located in Amhara National Regional State.

Analysis of the daily collected data took place side by side of data collection. The in depth interviews, focuses group discussions and observations were carried out until we totally failed to get new information.

Water-pipe tobacco has different names such as Nargila, Hookah, Hubble-Bubble, Water Pipe and Shisha in deferent countries. In this paper we used water-pipe to cover all these different names as recommended by WHO, 2006 [7].

This study was approved by Ethics Review Committee of Bahir Dar University. Participant information sheet were given for all the participants. Interviews, focus group discussions and observations were conducted after informed consent was obtained from each study participant. Some study participants declined to participate in the study by disagreeing the tape recording.

\section{RESULTS AND DISCUSSION}

A total of 115 (43 women and 72 men) took part in the interviews and FGDs. Their ages ranged between 16 and 48 years old. Table 1 displayed the socio-demographic characteristics of study participants. As shown in the table, nearly $50 \%$ of the study participants were people at the age of 25 years and below. More than $80 \%$ of the study participants were below 40 years of age. More than $30 \%$ of the study participants were students. This finding is supported by several documents produced by World Health Organization [17]. These and others literature in the field indicate that teens, and youth younger than 20 years are the common consumers of flavored tobacco [18, 19].

Though more than $50 \%$ of them were single in their marital status, married ones also accounted for more than
Table 1. Socio demographic characteristics of water-pipe tobacco smokers, Bahir Dar City, 2013.

\begin{tabular}{|c|c|c|}
\hline Variables categories & Frequency & percent \\
\hline \multicolumn{3}{|l|}{ Age group } \\
\hline $16-25$ yrs & 56 & $48.6 \%$ \\
\hline $26-35$ yrs & 41 & $35.6 \%$ \\
\hline $36+\mathrm{yrs}$ & 18 & $15.6 \%$ \\
\hline \multicolumn{3}{|l|}{ Educational level } \\
\hline Able to read and write & 3 & $2.6 \%$ \\
\hline Elementary completed & 18 & $15.6 \%$ \\
\hline High school completed & 27 & $23.4 \%$ \\
\hline University student & 29 & $25.2 \%$ \\
\hline Diploma & 19 & $16.5 \%$ \\
\hline Degree & 13 & $11.3 \%$ \\
\hline Degree+ & 6 & $5.2 \%$ \\
\hline \multicolumn{3}{|l|}{ Marital status } \\
\hline Single & 65 & $56.5 \%$ \\
\hline Married & 26 & $22.6 \%$ \\
\hline Divorced & 8 & $6.9 \%$ \\
\hline Widowed & 12 & $10.4 \%$ \\
\hline Separated & 4 & $3.4 \%$ \\
\hline \multicolumn{3}{|l|}{ Religion } \\
\hline Orthodox & 67 & $58.2 \%$ \\
\hline Muslim & 46 & $40 \%$ \\
\hline Others & 2 & $1.7 \%$ \\
\hline \multicolumn{3}{|l|}{ Occupation } \\
\hline House wife & 2 & $1.7 \%$ \\
\hline Daily laborer & 16 & $13.9 \%$ \\
\hline Merchant & 15 & $13.0 \%$ \\
\hline Broker & 20 & $17.3 \%$ \\
\hline Government worker & 8 & $6.9 \%$ \\
\hline Private worker & 17 & $14.7 \%$ \\
\hline Student & 37 & $32.1 \%$ \\
\hline \multicolumn{3}{|l|}{ Monthly income } \\
\hline Less than 600 & 31 & $26.9 \%$ \\
\hline 601 up to 1500 & 20 & $17.3 \%$ \\
\hline 1501 up to 3000 & 28 & $24.3 \%$ \\
\hline 3001 up to 5000 & 21 & $18.2 \%$ \\
\hline $5000+$ & 15 & $13.0 \%$ \\
\hline
\end{tabular}


20\%. Generally, people from almost all walks of life were found in the selected lounges and participated in this study. This finding is also supported by studies elsewhere $[20,21]$.

Almost all of the study participants claimed to be tobacco naive before they started smoking water-pipe tobacco. For people in the study area, however, to be tobacco naive is the norm not the exception. Sad is that they started smoking aromatic water-pipe tobacco without being informed that they were smoking tobacco which contains harmful substances at least as equal as cigarettes. Researches indicate that even in areas where smoking tobacco is pretty common, more than $30 \%$ of water-pipe tobacco smokers were tobacco naïve before they started smoking aromatic water-pipe tobacco [20]. A study conducted by Khaled Aljarrah et al. 2009 [19] revealed that more than $70 \%$ of water-pipe tobacco smokers were tobacco naive. This shows that aromatic tobacco is very much deceptive and dangerous as well.

The findings of this explorative study were categorized in nine major themes.

1) Khat chewing experience as a precursor for Water-Pipe tobacco smoking.

2) Economic accessibility

3) Geographic accessibility

4) Attractive water pipe apparatus,

5) Attractive and aromatic tobacco flavors.

6) Peer influence

7) Lack of knowledge about the contents of water-pipe tobacco

8) Absence of effective policy

9) Attractive income source for the owners of the lounges.

Most of the themes identified in this study are supported by a qualitative study conducted in Lebanon [22]. They identified the following themes: availability, affordability, innovation, influence of media, lack of a policy framework, and the sensory characteristics evoked from WTS. This might indicate that the driving forces behind increment of water-pipe tobacco smoking are similar across the globe.

\subsection{Khat Chewing Experience as a Precursor for Water-Pipe Tobacco Smoking}

Of the total 115 study participants only 7 (6\%) had started water-pipe tobacco smoking before having any experience with Khat. Participants indicated that before they smoked water-pipe tobacco they must chew khat.

A 27-year-old male with 3 years experience of waterpipe tobacco smoking expressed his experience as follows:

"Water-pipe tobacco makes everybody calm down who chewed Khat that is why we like it As to me," he said, "I must get high MERKANA" with the feeling of khat first and then I wanted to smoke shesha because it will help me come down to my relatively normal state other- wise it is very difficult for me to calm down.”

Another focus group discussant supported this view. "if I smoke shesha only without chewing khat, it will make me dizzy for the whole day and it will make me sleep. I can not even puff 6 or 7 times if I did not chew khat" (female, 32 years old with 5 years water-pipe tobacco smoking experience.)

This perception was shared by most participants. "Khat stimulates, and water-pipe tobacco calms down," they said. The finding of the present study shows that the major segment of the water-pipe tobacco smokers in the city had been Khat chewers, but they were not exposed to any other tobacco before.

People take khat to be stimulated, and then smoke water-pipe to calm down. That means the over-stimulating effect of khat requires the calming down effect of water-pipe tobacco. By doing so, young people start completely ruining their health in a region where tobacco naive communities had the chance to nurture their children in a tobacco free environment. Is that not sad?

This finding, according to the investigators, seems to be peculiar to Ethiopia. We have not encountered other studies outside Ethiopia that reported this kind of constellation of addictive substances that foster one another to ruining innocent communities who had livid for thousands of years in a tobacco free environment.

\subsection{Geographic Accessibility of Water Pipe Tobacco in the City}

Study participants claimed that all inputs required for water-pipe tobacco smoking were abundant in almost every shop in the city. This availability of water-pipe lounges in all the kebeles was thought to have contributed to the increase in its use. FGD participants stated that easily accessibility motivated even those who didn't even want to try. Women smokers repeatedly mentioned that widespread availability of water-pipe tobacco as the reason behind the increase in water pipe smoking trends. This finding is supported by reports everywhere. For instance, Non-Smokers' Rights Association (2012) [12] reported that WPT lounges are booming in Canada. A study conducted by Nekash et al. (2011) [22] indicates also that water-pipe tobacco smoking facilities are coming to be a precondition for cafes and restaurants to be visited in some middle east countries including Lebanon.

Many of the participants of the present study were very much skeptic whether water-pipe tobacco is illegal in Ethiopia. They said that if it were genuinely illegal why they were able to buy it in all the shops in Bahir Dar City. They said, "one could go and buy a pack of Maasel with apple smoking aroma for only 30 Birr." 
"Shesha and Khat lounges are all over the dirty corners I wonder why they are calling them illegal while people make business in the day time." (female, 28 years old with 2 years experience of water-pipe tobacco smoking)

Moreover, three focus group discussants stated that they smoked water-pipe in Addis Ababa. There, they said, "people smoked at clubs freely without any interference, and hence, they thought that it was legal”. Therefore, they could not understand why it was not legal in Bahir Dar City”.

\subsection{Economic Accessibility of Water Pipe Tobacco Smoking}

Study participants claimed that water-pipe tobacco was affordable. You can smoke in the lounges or at home for affordable price.

However, some lounges in the city may charge an entrance fee of about 5-10 Birr. Those clients who wanted their privacy could get a single room which could cost 50 to 80 Birr for the whole day. For those who want to sit in a circle, they call it JEMEA, the cost could be cheaper.

The duration of a 2 gram tobacco using water-pipe varies depending on various factors such as how many smokers were sharing, and how often they puffed; but most of them agreed that it might last between 15 to 20 minutes.

Participants claimed also that there was a possibility for those who want to smoke at home. These clients could rent the apparatus with all the accessories for up to 50 Birr a day. The accessories could be used repeatedly. Additionally, they could buy one pack maasel for just 30 Birr if they go to normal shops. This finding is in agreement with a report from USA [8]. The report of the association highlights that the cost of water-pipe tobacco is affordable for young people to share, and have fun together.

\subsection{Attractive Water Pipe Apparatus}

Study participants claimed that the apparatuses did have beautiful and sexy figure made of different materials and its cost varies from 300 to 2500 Birr. These apparatuses were claimed to be smuggled from Sudan, Yemen and United Arab Emeritus.

"I like the style of the apparatus, the different types of the hoses and even the way of preparation; it resembles Ethiopian coffee ceremony. Water-pipe has its own attractive ceremony." (female, 30 years old with four years experiences of water-pipe tobacco smoking)

Similar expressions had been heard from study participants in Lebanon in study conducted by Nakkash and colleagues (2011) [22]. As a female WPT smoker from rural Lebanon put it: "you put rose petals on the plate, you change its hose, paint it... At the end you will like the way it looks. If the water-pipe looks nice and clean, then you would have the desire to smoke."

Another male smoker in rural Lebanon also expressed his feelings and impressions as follows:

"I like the smoke when it comes out as it does... when I was not smoking the water-pipe, I used to look at someone who smoked it and see how the smoke comes out of it and that made me love it."

\subsection{Taste of Flavor and Aromatic Smell}

We have experienced more than 20 flavors of water-pipe smokes, said one of the FGD participants. Apple, grape, mint, chocolate, banana and wine were the most common ones but APPLE was the best choice. The company of every body's choice was ALFAKHR Tobacco Company based in United Arab Emeritus. The finding is supported by the reports from Cairo [6].

In contrast to cigarette, aromatic water-pipe tobaccos smell like fruits. This makes aromatic water-pipe tobacco special and attractive, everyone in the FGD agreed. A 19-year-old female with one year water-pipe tobacco smoking experience expressed her feeling as follows:

"I am a student and my parents don't know that I smoke water-pipe tobacco and the best thing about it is nobody knows whether I smoked or not even if I went home and kissed them they think I had a new perfume not a smoke and it made me safe."

This idea was shared by many of the study participants:

"When I pass by water-pipe tobacco lounges and smell the water pipe from the outside, I say that's it, I want to smoke it right away." (35-year-old male with 4 years water-pipe tobacco smoking experience)

\subsection{Peer Influence}

The younger age groups from the in-depth interview claimed that friends took them for the first time and since then they did not want to stop.

"My friends from high school used to come and ask me whether I had ever smoked water-pipe. My answer was no. They laughed at me and told me that failing to test it was not typical of a city boy. Then one day they took me there and we smoked together. Believe it or not, the day I tasted it, I have never stopped until now. For your surprise my friends who brought me here quit but I could not. It has been 4 years now, and I do not think I will stop." (male, 24 years old with 4 years smoking experience)

The sense of chewing khat and smoking of Ma'asal tobacco together with friends of the same age and even status were listed as main reasons for some to try waterpipe tobacco smoking. 
"me and my friends always come to water-pipe tobacco lounges even when we talk on the phone to meet somewhere everybody says I am inside the water-pipe smoking lounge come-over and it surprises me that some times 10 of us-friends-meet inside one water-pipe tobacco lounge." (male, 35 years old with 5 years smoking experience.)

Peer pressure does not seem to be confined among students, it happens also among adults having similar career. A discussant, driver by profession, expressed his experience as follows:

"we are all night time drivers from Bahir Dar to Addis Ababa; but before we go for a long drive we smoke water-pipe here and go to Addis Abeba together; we have been doing it for more than 2 years now.”

This finding is in agreement with findings of researches done by several researchers in different countries. Peer pressure and social acceptance are found to be important factors to smoke water-pipe tobacco currently $[8,23]$.

\subsection{Lack of Knowledge on the Contents of Water-Pipe Tobacco}

All the participants of the in-depth interview and FGD claimed that the advocacy of water-pipe tobacco has always been misleading in that water inside the water-pipe smoke filters all the harmful contents.

Some of the smokers complained about such a misleading description of water-pipe tobacco.

"I have lost my baby because I did smoke across all my pregnant period and then finally my pregnancy ended up in a still birth. I blame myself, and feel guilty but... here I am again.” (31 year old, female interviewee with 5 years water-pipe tobacco smoking experience)

This finding is supported by a study from Pakistan which revealed that about $70 \%$ of water-pipe tobacco smokers considered water-pipe tobacco as less deleterious to health than cigarettes [19,24].

Another interviewee expressed his belief about waterpipe tobacco as follows:

"I believe, he said, water-pipe tobacco is not addictive."

Different studies in different parts of the world indicate that water-pipe tobacco is assumed to be less addictive, and less harmful than other forms of tobacco such as cigarettes. This misconception is partly due to the assumption that water in the water-pipe apparatus filters all sorts of possible harmful chemicals [23,25,26].

Studies indicate that water-pipe tobacco contains several hazardous chemicals that can really be responsible for the occurrence of different kinds of diseases $[6,21$, $27,28]$. Even worse, reports indicate that it is very difficult to exactly tell the contents of water-pipe tobacco because there is a possibility to add anything in the mix- ture on site [12].

In this study, no one including the educated exactly knew the contents of water-pipe tobacco. The response of one of the study participants is presented hereunder.

"I think it is pure apple fruit." said a 40-year-old male teacher with 5 years experience of water-pipe tobacco smoking.

\subsection{Best Way of Income for the Owners of the Lounges}

Owners of water-pipe tobacco smoking lounges claim that they had a difficult but very much profitable, and easy to possess business. A total of ten people seven women, and three men were interviewed.

They said that to open a water-pipe smoking lounge one did not need much capital investment. To establish top ranking lounge in Bahir Dar one needs 15,000 Birr only. However, for 3000 to 5000 Birr one can establish a good lounge. The profit is more than three times. That is why people do not stop re-opening their lounge after they were confiscated, and punished. A lounge owner can make 300 to 800 Birr net profit per day in Bahir Dar.

A 35-year-old female interviewee put her impression of the business based on her own experience as follows:

"I don't think there is any other form of profitable business than selling shisha. For instance, take my case; I smoke for free because I am the owner and also make money: I finance my little sisters and brothers to visit a good privately owned school in the city. What do think?"

\subsection{Absence of Effective Policy}

Most of the FGD and in-depth interview participants claimed that they were caught by the police at least once while smoking. They explained about what polices usually did with them. Most of them said that the police took them to the police station, gave them some advice, registered their names and send them back home. Some of them said that they spend 24 hours in the police station. All the women said that they had been caught and taken to the police station and released after 2 or 3 hours. Almost all the participants were scared of being caught by the police because the information might be given to their family, or to the work place which could have negative implication.

In case of owner of water-pipe tobacco smoking, the action of the police was claimed to be different. Firstly, the owners, and the available materials for water-pipe tobacco smoking would be taken to the police station. All the materials were claimed to be confiscated, and additionally the owners would stay 3 to 4 days in jail, made to pay from 400 to 2000 Birr as financial punishment.

However, the punishment did not seem to be effective. A 35-year-old female with seven years experience of wa- 
ter-pipe tobacco smoking, and currently owner of a water-pipe tobacco smoking lounge expressed her experience as follows:

"After I was caught by the police, and released the first thing I did was to buy a new apparatus and continue selling and apologize my customers for the service interrupted."

Study participants were not sure whether there was any rule or regulation that legally prohibits water-pipe tobacco smoking in Ethiopia in general and in Bahir Dar City in particular. They complained of the action of polices in the city who try to ban water-pipe tobacco smoking without having any policy or proclamation in their hands.

A 41-year-old client with six years experience of water-pipe tobacco smoking expressed his feeling regarding the prevailing failure of the government to control water-pipe tobacco smoking in the city, and forwarded his recommendation what the government could do to control the water-pipe tobacco challenge in the study area.

"I believe, he said, water-pipe tobacco is not addictive so if I did not find it in the shops I could stop it; so the government's responsibility should be to raise awareness of the community, and to legalize or to completely ban it."

Other study participants had even negative attitude towards the action of the government. A 34-year-old male smoker, participant of an in depth interview, expressed his feeling regarding the action of the government as follows:

"It is not about our health or the diseases related to water pipe tobacco smoking that our government focuses; it is all about politics that if we sit together smoking or chewing we might talk about politics and that is why they hunt us down when smoking and that is not fair."

One of the focus group discussants expressed his view as follows to show the failure of the government policy:

"We pay VAT for daily bread, our basic necessities, but we did not pay any penny for our addictive luxuries, is that not ridiculous?"

Polices seemed to have difficulties of controlling the flourishing water-pipe tobacco smoking in this city. One of the chief police officers expressed the techniques they applied to catch smokers, and lounge owners as follows:

"To prevent information leakage, before we send our police force to every water-pipe lounge in the city, we kept it secret and all the nine police stations will start searching equally and we destroy lots and lots of apparatus but they keep coming back. It surprises me sometimes even a police out of duty have been caught smoking WPT."

A 28-year-old male in depth interviewee who had been smoking water-pipe tobacco since 2 years and was in jail for 24 hours being caught smoking water-pipe tobacco expressed his complaint as follows:

"I smoked shisha not hasish, why I was arrested? I could not understand."

One should not be surprised that our police are not able to differentiate different forms of tobaccos and addictive substances because such things are pretty new to our society. We were born and grew up in almost tobacco naïve environment in this Coptic Orthodox dominated part of the country.

After we finished the data analysis, two of the researchers went to the places our interviewees mentioned to check some of the observable things. We saw different kinds of water-pipe apparatus with their accessories; we visited the lounges, attended WPT smoking ceremonies, we asked the price of a pack of maasal in the shops and saw apple-produce of ALFAKHR tobacco company etc. Everything what our interviewee explained appeared to be true.

The most unforgettable of the expedition was the scene in the lounges. The rooms are suffocated. As our interviewee mentioned, they are located in areas where houses are old, and the environment is unclean-dirty corners.

One of the lounges is located behind the Kebele administration office. This lounge is one of the busiest lounges in the city. We asked ourselves how it was possible to run an illegal business just near to a government office? We asked people around that area. The answer we received was consistent with what we obtained from the police officer-one of the interviewee. He reported that there was a situation that they found a police officer in his free time smoking in WPT smoking lounges. These people over the streets near the lounge told us that the government officials are there to inform the lounge owners when polices are coming to control the lounges. That means lounge owners are paying informally to government officials to make sure that they would not be caught by the police uninformed.

We visited also two police stations. We asked duty police officers to show us some materials confiscated from the tobacco lounge owners. They told us that they would not keep them; they will burn or destroy them in the presence of the owners. Then we asked them to show us the areas where they dispose the burned or destroyed materials. They could not able to show us broken, burned or destroyed materials in the places. We had the feeling that at least some of the police officers are also involved in the business. This justifies partly why controlling WPT in this city is difficult.

This study suffers from all the limitation of qualitative study approaches. For instance, the result can not be generalized to the general population like that of survey research results. However, the number of people involved in the study are more than hundred, and that the socio- 
demographic characteristics of study participants represent the major socio-demographic characteristics of the population in the city, hence, we hope that the finding of this study can give a highlight about the current situation of WPT smoking practices in Bahir Dar City, the capital of Amhara National Regional State.

\section{COCLUSION}

It appears that lenient government policy, lack of knowledge in the community about the contents of WPT, probably traditional tendency of communities to spend time together enjoying ceremonies of coffee, and recently khat in concert with poorly organized public health action seems to create a fertile land for the swift expansion of water-pipe tobacco smoking in this city. Water-pipe tobacco smoking is going to be another new and serious public health challenge for Ethiopia. Combination of addictions-khat chewing with water-pipe tobacco smoking seems to be typical to Ethiopia as far as our knowledge is concerned. This constellation of deadly additions warrants rigorous investigations, and their expansion should be met with appropriate measures sooner or later.

\section{ACKNOWLEDGEMENTS}

We are very grateful to GAMBY P.L.C for the scholarship given to our student-Mr. Amanuel Eshetie. Our heartfelt gratitude goes also to Bahir Dar University for collaborating with the GAMBY College of Medical Sciences to run a post graduate program in Public Health. Our gratitude goes also to Prof. Andreas Ruppel of University of Heidelberg, Germany, for his professional advice, and commitment to keep University to University links alive since more than a decade now.

\section{REFERENCES}

[1] World Health Organization (2004) Tools for advancing tobacco control in the 21st century tobacco control legislation: An introductory guide. Geneva.

[2] World Health Organization (2008) WHO report on tobacco epidemic. MPOWER Package. Geneva.

[3] Smoking and Health Action Foundation (2013) Waterpipe smoking: Bubble trouble.

[4] Shane MacGuill (2012) Japan tobacco extends scope with acquisition of the world's largest Shisha manufacturer. Euro-Monitor International.

[5] Maziak, W. (2008) The water-pipe: Time for action. Addiction.

[6] WHO (2006) WHO the health hazards of smoking Shisha. Regional office for the Eastern Mediterranean. Cairo.

[7] Egyptian Smoking Prevention Research Institute (2006) Tobacco use in Shisha: Studies on water-pipe smoking in Egypt/WHO Regional Office for the Eastern Mediterranean.

[8] American Lung Association (2009) An emerging deadly trend: Water-pipe tobacco use.
[9] Akl, E.A., Gunukula, S.K., Aleem, S., Obeid, R., Jaoude, P.A., Honeine, R. and Irani, J. (2011) The prevalence of water-pipe tobacco smoking among the general and specific populations: A systematic review. BMC Public Health, 11, 244. http://dx.doi.org/10.1186/1471-2458-11-244

[10] Chaouachi, K. (2009) Hookah (Shisha, Narghile) Smoking and environmental Tobacco smoke (ETS). A critical review of the relevant literature and the public health consequences. International Journal of Environmental Research and Public Health, 6, 798-843. http://dx.doi.org/10.3390/ijerph6020798

[11] Federal Institute for Risk Assessment (BFR) (2009) Frequently asked questions about water-pipe.

[12] Non-Smokers' Rights Association (2012) Water-pipe smoking in Canada: New trend, old tradition.

[13] Reda, A.A., Moges, A., Biadgilign, S. and Wondmagegn, B.Y. Prevalence and determinants of Khat (Catha edulis) chewing among high school students in Eastern Ethiopia: A cross-Sectional Study. PLOS ONE, 7, e33946. http://dx.doi.org/10.1371/journal.pone.0033946

[14] Colzato, L.S., Ruiz1, M.J., Van den Wildenberg, W.P.M., Hommel, B. Khat use is associated with impaired working memory and cognitive flexibility. PLOS ONE, 6, e20602. http://dx.doi.org/10.1371/journal.pone.0020602

[15] Dessie, G. (2013) Is khat a social ill? Ethical arguments about a "stimulant" among the learned Ethiopians. ASC Working Paper African Studies Centre, Leiden.

[16] Dhaifalah, I. and Šantavy, J. (2004) Khat habit and its health effect. A natural amphetamine. Biomed Papers, 148, 11-15. http://dx.doi.org/10.5507/bp.2004.002

[17] The scientific basis of tobacco product regulation: Report of a WHO study group. WHO technical report series.

[18] Korn, L., Harel-Fisch, Y., Amitai, G. and Social and Behavioral Determinants of Nargila Smoking among Israeli Youth (2008) Findings from the 2002 HBSC survey. Journal of Substance Use, 13, 225-238. http://dx.doi.org/10.1080/14659890701682220

[19] Aljarrah, K., Ababneh, Z.Q. and Al-Delaimy, W.K. (2009) Perceptions of hookah smoking harmfulness: Predictors and characteristics among current hookah users. Tobacco Induced Diseases, 5, 16. http://dx.doi.org/10.1186/1617-9625-5-16

[20] Azab, M., Khabour, O.F., Alkaraki, A.K., Eissenberg, T., Alzoubi, K.H. and Primack, B.A. (2010) Water pipe tobacco smoking among university students in Jordan. $\mathrm{Ni}$ cotine \& Tobacco Research, 12, 606-612. http://dx.doi.org/10.1093/ntr/ntq055

[21] Cobb, C.O., Shihadeh, A., Weaver, M.F. and Eissenberg T. (2011) Water-pipe tobacco smoking and cigarette smoking: A direct comparison of toxicant exposure and subjective effects. Nicotine \& Tobacco Research, 13, 78-87. http://dx.doi.org/10.1093/ntr/ntq212

[22] Nakkash, R.T., Khalil, J. and Afifi, R.A. (2011) The rise in narghile (shisha, hookah) waterpipe tobacco smoking: A qualitative study of perceptions of smokers and non smokers. BMC Public Health, 11, 315. http://dx.doi.org/10.1186/1471-2458-11-315

[23] Ray, C.S. (2009) The hookah-The Indian water-pipe. 
Current Science, 96, 25.

[24] Sameer-Ur-Rehman, S.M.A., Parekh, M.A. and Zubairi, A.B.S. (2012) Cross-sectional study identifying forms of tobacco used by Shisha smokers in Pakistan. JPMA, 62, 192.

[25] Action on Smoking and Health (2010) Fact sheet on water-pipes. www.ash.org.uk

[26] Daniels, K.E. and Roman, N.V. (2013) A descriptive study of the perceptions and behaviors of water-pipe use by university students in the Western Cape, South Africa. Bio Med Central. Tobacco Induced Diseases, 11, 4.
[27] Schubert, J., Kappenstein, O., Luch, A. and Schulz, T.G. (2011) Analysis of primary aromatic amines in the mainstream water-pipe smoke using liquid chromatography electro spray ionization tandem mass spectrometry. Journal of Chromatography, A. 12, 5628-5637.

[28] Eissenberg, T. and Shihadeh, A. (2009) Waterpipe tobacco and cigarette smoking. Direct comparison of toxicant exposure. American Journal of Preventive Medicine, 37, 518-523. 